\title{
Re-thinking Representation: Shifting Relations between Museums and the Indigenous Peoples of Taiwan
}

\author{
Shih-Yu Chen \\ International Ironbridge Institute for Cultural Heritage. \\ University of Birmingham \\ Birmingham, United Kingdom \\ Syc251@bham.ac.uk
}

\section{Abstract:}

The museum is a powerful site of representation; 'Which' objects and 'how' they are displayed engenders issues of ownership and carries a symbolism which has social and political consequences. This paper will look at the changing relations between museums and the Indigenous communities of Taiwan and how these relationships are manifest in the museums' collections, exhibitions and communication strategies.

To provide historical context and trajectories of change, I examine how the Indigenous peoples of Taiwan were represented in museums and exhibitions in early $20^{\text {th }}$ century colonial regimes. I then discuss changes in the representations of indigenous peoples within post-war Taiwan and how these changes relate to the complex search for national identity which invokes echoes of the Japanese colonial period and the dominance of Han Chinese heritage. I utilize James Clifford's idea of the museum as a contact zone to explore strategies of "culture-collecting" and the extent to which this can be seen as a response to particular political conditions, such as histories of dominance, hierarchy, and resistance. As contact zones, museums can help communities negotiate difficult cultural and political problems through dialogue and alliances. Furthermore, in order to identify some of the key themes which also relate to Taiwan, the paper will draw upon cases of emerging partnerships and collaborations between Indigenous communities and museum sectors to examine how these assist in re-thinking issues around the representation of indigenous peoples by asserting new political relationships through their material culture (Hendry 2005).

Keywords: museum, Indigenous peoples, representations, politics

\section{INTRODUCTION}

The population of Indigenous peoples in Taiwan is 2.3 percent $(534,007$ peoples) of a total national population of 23.5 million (MOI 2014). Until 2014, there were sixteen tribes that were officially recognized by the authority. The position of Indigenous peoples in Taiwan has changed over the years, and these changes are reflected in their relationships with museums, from representation as cultural others to being regarded as a symbol of social diversity.

In order to examine the relationship between Indigenous peoples and museums in Taiwan, this paper will first look at representations of Indigenous peoples during the Japanese colonial period (1895-1945) to as 
well as the political changes after the 1980s, when martial law was lifted, to discuss how have Indigenous peoples became critical to the Rainbow nation approach. Introducing the idea of representation in museums may help to give a clear picture of how Indigenous peoples' roles and positions have changed in Taiwanese society. In the final section, I will consider some of the challenges presented when major museums and Indigenous cultural communities collaborate.

Museums are considered part of the national authority in Taiwan since the political climate changed, putting greater emphasis on cultural diversity and marginal groups' rights. Because of this shift, museums began to reconsider their representations of Indigenous peoples. However, the influences of the past, such as the prestigious status of museum professions and the unequal distribution of resources among museums, are still felt, making representation an under-considered question. I argue that examining relationships between Indigenous communities and museums may help us to understand Indigenous peoples' current and future challenges.

\section{Methodology}

I adopt a 'mixed methods' approach to this study in order to examine the inter-relationships between Indigenous Communities and Museums in Taiwan. This involved in-depth interviews with key actors in both the museum sector and in the communities themselves. It also involved narrative analysis of existing displays and exhibitions. Initially I sought to examine the ways in which these communities are currently represented through the main 'National' Museums of Taiwan. This involved the identification and analysis of the objects and narratives which are on display there. It also involved interviews with the curators at these museums to explore what relationships they have with the Indigenous Communities and how such relationships have developed and are maintained. I interviewed some of the key activists amongst the Indigenous Communities to explore how they see the role of the museum and the museum sector in representing their heritage, culture and their social and political issues.

\section{REPRESENTATIONS OF INDIGENOUS PEOPLES IN TAIWAN DURING THE COLONIAL PERIOD}

Indigenous peoples are those groups believed to have arrived in Taiwan first. Until 2014, there were sixteen tribes that were officially recognized: the Amis, Paiwan, Tayal, Bunun, Puyuma, Rukai, Cou, Saysiat, Yami, Kavalan, Truku, Salizaya, Seediq, Hla'alua, and Kanakanavu. Prior to the Japanese colonial period, Indigenous peoples coexisted with the Han Chinese, the other significant group in Taiwan during this time. Like colonial powers in other parts of the world, the Japanese colonial government developed systematic and comprehensive control, with the ultimate goal of assimilating the Indigenous peoples into Japanese society. In order to categories and have a comprehensive control on Indigenous peoples, Japanese colonial government conducted studies which covered wide range of subjects, such as ritual traditions, tribal social systems, biology, and etc. (Suenari 2006). The notion of social evolution was believed by the Japanese, with the intention to 'civilise' Indigenous peoples, "the Japanese portrayed and catalogued Taiwanese Indigenous peoples through a welter of statistical tables, magazines and newspaper articles, [and] photograph albums for popular consumption" (Matsuda 1997). The Indigenous peoples were placed at a lower level on the evolutionary scale than the Han peoples and Japanese.

In order to civilize the Indigenous peoples, Japanese colonial government adopted several methods to enforce Indigenous peoples to take on Japanese customs as well as the Japanese identity. As Spurr (1993) states, the idea of the 'cultural other' plays a critical role in Japanese colonisation, particularly through material representation as objects become evidence supporting the categorisation of Indigenous peoples in a subordinate position. Through distancing Indigenous peoples, the Japanese could manage the threat they 
represented and create good reasons to rule over them. Bourdieu (1984) argued that an Indigenous collection, is "made not twice, but a hundred times, by all those who are interested in it, who find a material or symbolic profit in reading it, classifying it, deciphering it, commenting on it, combating it, knowing it, and possessing it." Representations of the Indigenous peoples changed according to Japanese concerns. For example, the tale of 'Sayon', in which a seventeen-year-old aboriginal woman volunteers to carry Japanese luggage to the mountain during the war in 1938 and sacrifice herself, was used to encourage Indigenous peoples' patriotism in order to shape them into loyal imperial subjects (Ching 2006).

The Japanese started to collect Indigenous artifacts in the later period of their occupation, generally regarding these objects as evidence of Indigenous 'primitiveness'. These collections were displayed at various events, for example, the Exhibition of the Twentieth Anniversary of Colonization in 1916 and the Exhibition of the Fortieth Anniversary of Colonization in 1935. Indigenous artifacts were also exhibited in Japan, at such events as the Fifth Domestic Industrial Exhibition held in Osaka in 1903, the purpose of which was to acquire the Japanese public's consent on the ruling authority by making the public feel superior to the colonized Taiwanese (Hu 2007). In such exhibitions, the Japanese represented the Taiwanese Indigenous peoples as 'cultural incompetents, morally suspect, and indeed somehow 'fictive' and distinct from the real thing' (Thomas 1991) in order to justify Japanese colonialism. Unlike previous representations that were created to justify colonial power, the purpose of attending International exhibitions was to present distinctive images of Japanese political and economic power, inherited Oriental traditions, and a high degree of modernization. Taiwanese Indigenous peoples were also represented to Western countries on some occasions, such as the International Exhibition in Paris in 1900, and the Louisiana Purchase Exposition in St. Louis in 1904 (Thomas 1991).

In these exhibitions, aside from any political intentions, Indigenous artifacts were also romanticised, displayed for their exotic beauty and craftsmanship. During the Japanese colonized period, although many traditions had been eliminated because they were deemed unsavory by the Japanese culture, such as tattooing, Indigenous peoples were also encouraged to maintain some of their traditions, such as dress and selected customs, which were not considered to be detrimental to society. The Japanese believed that the Taiwanese Indigenous peoples should be modernized and civilized and that those Indigenous cultural practices deemed acceptable by the Japanese should be preserved.

\section{INDIGENOUS POLICIES AFTER 1989}

After World War II, the island was under the rule of the government of the Republic of China (R.O.C.). It is therefore common to divide the past 75 years into two periods, the first covering 1937 to 1989 and the second from 1989 to the present, as martial law was lifted in 1989. After martial law was lifted Taiwanese society experienced dramatic differences, especially in the realm of equal rights and human rights for minorities, such as the Indigenous peoples. After 1989, Taiwanese society is considered to have entered the democratic era, a time of great change for the aborigines, in both constructive and destructive ways. The establishment of the Alliance of Taiwan Aborigines (ATA, or yuan chuan hui) in 1984 in particular is considered as a significant moment in the history of the Indigenous rights movement in Taiwan, as it gave the movement a stronger voice in solutions for social problems related to the aborigines. Economic and social disadvantage are considered to be the main difficulties affecting Taiwanese Indigenous peoples, and the establishment of the ATA raised greater awareness of the issues Indigenous communities commonly face, such as prostitution, economic hardship, claims to land rights and name rights (Faure 2001, Stainton 1999 and Hsieh 2006 ). 
During the early stage of the ruling period of the Kuomingtang (KMT), the national party, the Indigenous peoples of Taiwan were characteristised by their 'backwardness' and need to be 'Hanized'. However, after martial law lifted and the idea of 'New Taiwanese' became popular, the KMT began to represent the Indigenous peoples of Taiwan as pioneers who protected the island in order to win support from the aborigines, and appeal to anti-Japanese mainlanders, who fought against them during WWII. In 2008, political power shifted from the KMT to the Democratic Progressive Party (DPP), the largest opposition party, and this is considered to be the period in which Taiwanese Indigenous peoples began to be recognised in the country. With the emergence of new Taiwanese identities, as illustrated by DPP candidate Chen ShuiBian's election strategy that emphasized on Indigenous cultures and localism in order to be distinguished from Chinese. From this time on, Taiwanese Indigenous people have been widely recognised and involved in national and international events. For example, Indigenous singers were invited to lead the national anthem on National Day in 2000 and at the flag-raising ceremony on New Year's Day in 2002. As a response to this shift, including Indigenous cultures in contemporary museums has become a way of contributing to this democratic and equal impression. Indigenous peoples in Taiwan have shifted from being ignored and silent to having a voice.

\section{MUSEUMS AS CONTACT ZONES IN TAIWAN}

According to Clifford, museums are not only for exhibiting material objects, but also become 'contact zones' for objects and people from different places and cultures. Museums, "rather than simply educating or edifying a public, [ . . ] begin to operate - consciously and at times self-critically - in contact histories" (Clifford 1997). Museums are places where Indigenous peoples may show other perspectives of the same period of history that run counter to the narrative written in textbooks.

Currently, many museums would claim that they include Indigenous peoples in the preparation of representing Indigenous peoples in Taiwan, yet it is very rare to find their participation in permanent exhibitions. It is instead very common to find Indigenous peoples' works in temporary exhibitions. However, there are various types of involvement and roles for Indigenous peoples in these exhibitions, such as consultants, temporary curators and so on.

\section{A. Inidgenous peoples as consultants}

Most permanent exhibitions were created in an era that saw museums as educational institutions, and so it was important that museums deliver the 'facts' of Indigenous society. Rather than presenting history from many different perspectives, which could cause arguments, museums emphasised a portrait of Indigenous peoples, from clothes and ritual ceremonies to social systems. In particular, representing the Indigenous peoples of Taiwan as a way of highlighting the differences between them and the majority Han Chinese was a common practice for decades. This may have been useful in educating the public about the Indigenous cultures of Taiwan, but it also served to separate Indigenous peoples from other groups. This emphasis on their cultural differences also had the consequence of neglecting their participation in history. During the conflict period, the suppressive policy often resulted in only mainstream perspectives having the opportunity to be heard, with Indigenous peoples being represented as 'others' and often considered either as enemies or frozen in the past.

However, when awareness of the cultural right for Indigenous peoples to speak for themselves began to take hold, almost every museum worked with Indigenous communities in the process of renovations. Indigenous peoples' involvement as consultants is the most common model. Both permanent and temporary exhibitions would invite Indigenous peoples to examine and confirm the represented information. 
Furthermore, it is also common for Indigenous peoples to be involved in recreating their traditional architecture, such as gathering houses, or recreating their ritual surroundings. The Shung Ye Museum of Formosan Aborigines (SYM) is particularly aware of the differences among Indigenous groups as well as within each group, and they therefore also identify the name of the contributors and their ethnic groups on the boards (interview 2015). By doing this, visitors not only become aware that the information applies to specific groups or tribes but also develop an appreciation for the diversity of the Indigenous peoples of Taiwan. In addition, pointing out the contributors gives the involved Indigenous peoples due credit and responsibility for the representations.

Although it has been acknowledged that there is room for more Indigenous involvement, for more opportunities to speak for themselves, and that this would be more appropriate in representing the history of Taiwan's Indigenous peoples, there are still some difficulties to be faced. One of the main concerns is their audience. Most of the national museums are further away from the Indigenous public, and thus, most of their audience is composed of non-Indigenous visitors who are assumed to have less knowledge about Indigenous cultures. There is a fear that detailed information may lose their interest. The other main difficulty concerns limitations of space. It is impossible for museums to cover all aspects of Indigenous cultures, therefore, permanent exhibitions are considered as the first stage of understanding Indigenous peoples, as the director of the SYM states,

Concerning the limitation of space, the museum puts its focus on introducing the characteristics of the

Indigenous peoples in Taiwan. On the first floor we have the whole picture of the Austronesian. Peoples who live in the mountain area and seaside are different. On the second floor we have their lifestyles and the

female world on the top floor and the ritual world on the bottom one. After visiting all the floors, our visitors would have a clearer general idea about the Indigenous peoples in Taiwan (interview 2015).

The curators of the National Museum of Taiwan History (NMTH) also mentioned the purpose of their permanent exhibition is

Through the main story to present the general history of Taiwan could give visitors the idea of the Indigenous peoples'status and positions at that time. It cannot be denied that there are some aspects that would be excluded but we could deal with those issues with more details in later temporary exhibitions

(interview 2015).

The above interview quotes indicate that the most common way for museums to represent Indigenous peoples is to have a permanent exhibition that offers general information, and significant differences can be elaborated on in temporary exhibitions with more specific information, as well as deeper, more detailed insights from Indigenous peoples. When a general exhibition is being built, it is not surprising to find the involvement of Indigenous peoples limited, since detailed traditional knowledge may not be represented.

\section{B. Indigenous peoples as temporary curators}

It is not very common to see museums invite Indigenous peoples to curate their own work. The National Taiwan Museum (NTM) held a temporary exhibition with two Indigenous artists in 2014. One was Yuma Taru from Atayal, who brought back the techniques of traditional cloth weaving and dying. The other was Remereman from Peiwan, who specialises in making traditional glaze with modern style. According to the director, it was the first time that the museum invited Indigenous artists to become curators (interview 2015). The artists had authority over which of their works to present and how. Because the exhibition was about artwork and not a controversial representation, the most difficult problem for the museum was balancing the artists' requests, from budget sharing to allocation of exhibition space to press attention. From 
the museum's point of view, working with Indigenous curators was an educational process; the way these Indigenous artists liked their works to be presented was different from the way the museum might have done it. Although it cost the museum significant time and effort to work with Indigenous curators, particularly with artists who might have artistic demands that required more negotiation than was usual, the curating process was also an opportunity to understand how these Indigenous peoples would choose to be represented (interview 2015). However, sharing authority with Indigenous peoples could be considered a great challenge that museums may be reluctant to take on. Some museums see themselves as educational institutions. Apart from presenting aesthetic objects, the message Indigenous participants intend to deliver also needs to be taken into consideration. Indigenous participants may hold opinions that are controversial or considered incorrect, which could force museums to face the dilemma of whether to accept Indigenous peoples' self-recognition or insist on remaining accurate. For example, both the Paiwan and Rukai tribes are known for their speciality in making pots, which are not only functional objects but also sacred symbols. In an exhibition, when the museum collected or borrowed these objects that the Indigenous artist believed to be from his own tribe, it transpired that the objects were actually from the other tribe. The mistake was discovered during the preparation, and although the museum could indicate that it was the artist's opinion, the museum may still have to face criticism and potentially lose credibility (interview 2015).

As Golding $(2016,2)$ has shown, different groups and communities can be connected by museums and their collections, in museum collaborative works, museum space become a "spacial-temporal site for acting in collaborative effort with other institutions, which provides a creative space for respectful dialogical exchange, promoting critical thought, questioning taken-for-granted ideas in general and for challenging racist and sexist mindsets". Similar incidents can also be found in other museums, showing that, although there are great differences between tribes, through intermarriages, traveling and other interactions, Indigenous peoples have adopted and learned from other tribes and even other ethnic groups. Working with Indigenous artists who are influenced by their traditions as well as contemporary issues can give museums the opportunity to represent the 'fluidity' in Indigenous cultures in Taiwan, as well as exhibit their historic collections in a new way that may interest visitors. Furthermore, as the director of the NTM states, when it comes to representing Indigenous peoples, even when museums are aware of some mistakes, they tend to go with the Indigenous community's decision. For example, he describes one such incident as follows;

There is a stone coffin we borrowed for an exhibition in Feng-Bin community but somehow it ended up in our collection. Kebalan people came to us for repatriation years later, and claimed they have seen that coffin in their childhood. But according to archeology, that coffin has nothing to do with Kebalan. That was the heritage of Megalithic Culture three thousand years ago, and Kebalan was actually based in I-Lan but has moved to Hua-Lien because of Han dominance. But the museum gave it back in the end. [... ] Because the recognition of an Identity cannot be objective, we had a committee for the issue, everyone agreed that the Gavalan people was wrong about it, but since they took the coffin as their material identity, as long as the object will not be ruined, museums in Taiwan tend to treat issues of the Indigenous peoples and minority in the most tolerant way (interview 2015).

\section{Indigenous peoples as official curators}

The National Museum of Prehistory (NMPH) is the only national museum that has Indigenous curators. As permanent curators, they have access to the same resources as all museum staff. Indigenous curators therefore theoretically have more influence over representing Indigenous cultures.

Lin has curated several exhibitions on different communities. In each exhibition, focusing on a specific community allowed him to present more detail and work more closely with them. As Lin points out, the 
NMPH is located in Taitung county, which has the most Indigenous communities of any region of Taiwan. The museum thus has the opportunity to offer a deeper and more detailed perspective when representing indigenous cultures. The working relationships with Indigenous communities are, furthermore, different from museums in cities. For example, the temporary exhibitions in the NMPH are the result of collaborations with represented communities in ways that rarely happen in other museums. Due to the location of the museum location, it allows Lin to spend a great amount of time in Indigenous villages before the exhibitions opened and build his own network for potential future projects. His approach to working with represented communities was to develop exhibition ideas from his daily conversations with community members. Then, he and the represented communities would research the related history, stories or traditions surrounding the idea. Elders played critical roles in his research process. When representing Indigenous communities, he gave authority to the communities; From setting up the exhibition environment to narratives, he positioned himself as support to the represented communities to reach professional standards.

\section{I have some insistences when representing Indigenous peoples. I insist that it is necessary to report to the represented communities. It takes great amount of time to communicate, and I would like to have recognition from the represented community. Especially with the Indigenous community, there are contents that will come out better if I wait long enough. Therefore sometimes my colleague would complain that I shorten their working time for other processes(interview 2015).}

Lin also claims that his position gave him the resource and power to support represented communities, thus he insisted everything that was made for the temporary exhibitions should be taken back to them. By doing this, those communities could keep the research outcomes and carry on further development in their communities.

Because the NMPH is close to some Indigenous communities, the museum was able to offer some help when natural disasters happened. For example, a flood in 2009 caused tremendous chaos in Eastern Taiwan and many Indigenous communities were destroyed. The curator went to the site to help the community preserve objects, from traditional artifacts to family belongings. A year after the disaster, he bought those objects into the museum and put up a temporary exhibition to show the effects of the flood. The exhibition had a significant impact on helping the area to rebuild, as many visitors offered help after their visit to the museum. The represented community already had sufficient recourses to rebuild their community, and so forwarded this help on to other communities still in need. The exhibition made the public aware of the desperate living situation the community was in, and brought resources into that community and others, helping them to recover more quickly. The exhibition demonstrated how a museum could participate practically in natural disaster relief. Lin commented on the differences between his work and the work of other colleagues, for example, the amount of time he spent with represented communities, and his concerns about their further development.

Unlike other curators, I have fewer budget concerns when representing the Indigenous peoples, as long as I can pay the people who work for the exhibitions. Because of this, sometimes my exhibitions may not be as sophisticated as my colleagues'. My exhibitions would be done by ourselves with some cheap material sometimes, but I can afford it. I would also want to use better techniques to help the communities to put exhibitions together (interview 2015).

Museums have the potential to form new identities and new connections between vulnerable groups and their own past. The curator believes it is important to represent Indigenous peoples in national museums, and there should be support and resources for the represented communities. Although Lin's personal experiences cannot speak for all Indigenous curators in Taiwan, his significant closeness with Indigenous 
communities and cultures is worth consideration because of his strong connection with his own culture. This kind of passion is rarely found in other non-Indigenous curators.

\section{Inidgenous community curators}

The SYM invites one Indigenous community each year into the museum to speak for themselves. The museum offers financial resources and space, and the community is responsible for deciding the theme of the exhibition, collecting objects, and setting the exhibition hall. According to the director of the museum, it is very rare for the museum to intervene in the process, with the exception of running over-budget (interview 2015). The idea behind this type of representation was developed from one of the museum aims, that is, to take advantage of being a private museum and do things government-run museums cannot do. By offering such opportunities, it can help unite communities and help them to understand their precious history and cultures again. There are, however, some limitations to these community special exhibitions. Because they are completely managed by the represented communities themselves, from content to exhibition surroundings, they have been criticized as unprofessional or inefficient in delivering the represented message. It has been argued that tribal special exhibitions are welcomed within Indigenous communities, with many community members visiting the exhibitions, or even proposing to represent their own communities, since it is a very rare opportunity. Nevertheless, tribal special exhibitions have not drawn much attention in Taiwan, partly because they are located opposite the National Palace Museum, far from the city centre. Apart from tourists and school visits, they have few individual Taiwanese visitors.

The SYM has the advantage of not being limited by governmental policies, allowing them to present more controversial or sensitive issues. This advantage attracts communities that seek to present controversial issues or represent themselves in controversial ways. For example, the museum has represented the Siraya peoples who are considered one of the plain Indigenous groups. They claim to have Indigenous ethnicity, however, they have not yet been officially recognised at the national level. Therefore, in national museums, they can only be represented as a cultural group that has no Indigenous ethnicity. In the SYM, however, they are free to claim themselves as an Indigenous group.

The purpose of the exhibition is to tell people who we are, unlike the representations in the past that plain Indigenous peoples belong to history, I want to connect our history and our life in the present together. Let people know we have always been here (interview 2015).

As Galla (1997) argues, the "project is initiated either by the Indigenous community specialist or the external anthropologist" and both are co-workers on the project participating in shared decision making on the development, implementation and evaluation of the project. The process is "mutually empowering, with heritage communication between and among all participants" (ibid 152). These self-curated representations not only offer opportunities for Indigenous peoples to speak for themselves, but also allow them to present issues that are not necessarily welcome in national museums. Having full authority over representing themselves gives participant Indigenous communities some confidence and pride. However, as the Siraya cultural history office founder admits, during the preparation of the exhibition, they still needed to seek professional help, particularly around exhibition design and object presentation (interview 2015). Although there are increasing numbers of Indigenous peoples who are more educated than previously, it is still uncommon for Indigenous communities to contain people who have professional knowledge of anthropological research about themselves and have produced narratives for representation. As director Lin of the SYM states, tribal special exhibitions have shown that there are many novel ways of representing Indigenous communities. For these communities, the uniting process is more important than bringing in 
great numbers of visitors. Unlike typical museum representations, these tribal special exhibitions have fewer audience concerns, instead focusing on ways the community would choose to be represented.

\section{CONCLUSION}

Representations of Indigenous peoples in Taiwan have changed significantly in a short period, from being exploited to engaging autonomy. During the colonial period, they were often presented as 'others' in order to strengthen governmental authority or serve various colonial needs. With very little power to speak for themselves, it was difficult for Indigenous peoples in Taiwan claim their rights. With an awareness of human rights, Indigenous peoples became a critical culture for Taiwanese society. Institutions such as museums became important spaces in which these changes could play out. Similar to museums in other places of the world, such as Canada, Australia and New Zealand, including Indigenous cultures in contemporary museums became a way of contributing to a democratic and equal impression. Unlike Museum of New Zealand Te Papa Tongarewa where the Indigenous culture, Maori, shares an equal position with the dominant culture, and the Maori people are considered as partners rather than guests or consultants, although Clifford's concept of 'museums as contact zones' can also be found in Taiwanese museums, which consider Indigenous representation as an inevitable subject, the extent of equal communication and mutual learning in Taiwanese leading museums is still arguable. From the examination of the extent of Indigenous peoples' involvement in Taiwan shows that, although their voices are increasingly important and are more frequently heard in leading museums, the hierarchy between museums and the public still exists, the involvement of Indigenous peoples may still be controlled by the museums in order to fulfill their educational role and objective concerns. In spite of the fact that Indigenous collections have become a highlight in some museums, Indigenous peoples' participation still remains limited (Varutti 2012). There are still issues surrounding professionalism, access, power struggles and coordination.

\section{LIMITATION}

Due to the scope of this paper, this paper puts its emphasis on the leading museums in Taiwan, which is considered to be more influential than other exhibiting spaces on Indigenous representations. Nevertheless, in addition to the leading museums, the number of Indigenous representations has also greatly increased in smaller museums as well as in Indigenous communities. Although the representations that happen outsider the leading museums have not been discussed, the value of these representations cannot be denied.

\section{REFERENCES}

Bourdieu, Pierre. 1984. Distinction: A Social Critique of the Judgment of Taste. Trans. Richard Nice. London: Routledge \& Kegan Paul.

Chang, Yao-Chung. 2008. Nation vs. Tribe: The Change of Japanese Educational Strategies on Taiwan Indigenous People during 1895-1945, NTTU Educational Research Journal, 19 (2), 1—30.

Ching, Leo. 2000. 'Savage Construction and Civility Making: The Musha Incident and Aboriginal Representations in Colonial Taiwan.’ East Asia cultures critique, 8 (3), 795-818.

Clifford, James. 1997. 'Museums as Contact Zone' In Representing the Nation: A Reader Histories, Heritage and Museums, edited by Boswell, D. and Evans, J. London: Routledge. 
Faure, David. 2001. In Search of the Hunters and Their Tribes. Taipei: Shung Ye Museum of Formosan Aborigines Publishing.

Galla, Amareswar. 1997. "Indigenous peoples, museums, and ethics”. In G.Edson, ed. Museum Ethics. London: Routledge, 142-155.

Golding, Viv. 2016. Learning at the museum frontiers: Identity, race and power. Routledge.

Hendry, Joy. 2005. Reclaiming Culture: Indigenous People and Selfrepresentation. New York: Palgrave Macmillan.

Hsieh, Jolan. 2006. Collective Rights of Indigenous Peoples: Identity Based Movements of Plains Indigenous in Taiwan. New York, NY: Routledge, Taylor and Francis Group.

Hu, Chia-Yu. 2007 'Taiwanese Aboriginal Art and Artifacts: Entangled Images of Colonization and Modernization', In Refracted Modernity: Visual Culture and Identity in Colonial Taiwan, edited by Y. Kikuchi, 193 - 216. Honolulu: University of Hawaii Press.

Matsuda, Kyōko. 1997. "The Taiwan Aborigine Surveys during the Early Period of Japanese Rule: Focusing on Ino Kanore". In Studies in Taiwan History. 14, 135-148.

Ministry of Interior. June 2014. The Analysis of Census Statistic (民國 103 年 6 月 內政部戶口統計資 料分析). http://ppt.cc/NkTL (accessed 04/07/2014).

Simon, Scott. 2007. "Paths to autonomy: aboriginality and the nation in Taiwan". In The Margins of Becoming: Identity and Culture in Taiwan, Wiesbaden: Harrassowitz. : 221-240.

Spurr, David. 1993. "The Rhetoric of Empire: Colonial Discourse", In Journalism, Travel Writing and Imperial Administration. Durham: Duke University Press.

Stainton, Michael. 1999. "The Politics of Taiwan Aboriginal Origins" in Murray A. Rubinstein (Ed.). In Taiwan A New History. New York: M.E. Sharpe, Inc.

Suenari, Michio. 2006. "A Century of Japanese Anthropological Studies on Taiwan Aborigines." In History, Culture and Ethnicity: Selected Papers from the International Conference on the Formosan Indigenous Peoples. Taipei : Shung Ye Museum of Formosan Aborigines.

Thomas, Nicholas. 1991. Entangled Objects. Exchange, Material Culture and Colonialism in the Pacific. Cambridge, MA: Harvard Univ. Press.

Varutti, Marzia. 2012. "Towards social inclusion in Taiwan: Museums, equality and indigenous groups." In Museums, Equality and Social Justice, edited by Richard Sandell and E. Nightingale. Routledge.

Yorozu, T. M., Hirano, K. Oka, and Y. Tagawa, "Electron spectroscopy studies on magneto-optical media and plastic substrate interface,” IEEE Transl. J. Magn. Japan, vol. 2, pp. 740-741, August 1987 [Digests 9th Annual Conf. Magnetics Japan, p. 301, 1982]. 